\title{
LOS JOVENES Y LA REDEFINICION LOCAL DEL CONSUMO
}

\begin{abstract}
SERGIO DANIEL PAZ*
RESUMEN

Este trabajo pretende abordar una discusión en marcha sobre jóvenes, consumo y espacio a partir de sistematizar algunas ideas respecto a la relación entre transformación de la oferta comercial y cultura juvenil, y avanzar en el análisis de sus efectos sobre los ambientes locales socioeconómicos.

En el marco de las dinámicas que marcan la reestructuración del escenario metropolitano de Buenos Aires, los grandes centros comerciales y recreativos, merecen un especial tratamiento dado que se han erigido como nodos urbanos que internalizan recursos que permiten a los jóvenes clasificarse y clasificar a los demás, al tiempo que producen una redefinición, de carácter local, del consumo de estos espacios y sus bienes.

Diseño arquitectónico, música, decoración, integración funcional, eventos, incitación publicitaria, anuncios, exhibición de bienes, todo confluye para dar forma a la atmósfera comercial que mora al interior de estas grandes superficies comerciales y recreativas, donde se respira el fenómeno del consumismo. Dinámica económica que se ve complejizada con la postura activa por parte de los jóvenes que con sus prácticas sociales al interior de estos espacios recrean el escenario en el cual se encuentran sumergidos, con un fuerte impacto sobre los sistemas locales socioeconómicos.
\end{abstract}

PALABRAS CLAVE: JUVENTUD, CONSUMO, NUEVOS OBJETOS URBANOS

* Profesor del Programa Universidad Virtual de Quilmes, Universidad Nacional de Quilmes, Argentina. Investigador del Proyecto «Construir-Habitar-Pensar: nuevas modalidades de producción y gestión de la Región Metropolitana de Buenos Aires en el nuevo milenio», Universidad Nacional de Quilmes.

E-Mail: spaz@unq.edu.ar. 


\section{RESUMO}

Este trabalho pretende abordar uma discussão já existente sobre jovens, consumo e espaço com o objetivo de sistematizar algumas idéias a respeito da relação entre a transformação da oferta comercial e a cultura juvenil, e avançar na análise de seus efeitos sobre os ambientes locais socioeconômicos.

No marco das dinâmicas que marcam a reestruturação do cenário metropolitano de Buenos Aires, os grandes centros comerciais e recreativos, merecem um tratamento especial já que foram criados como espaços urbanos que internalizan recursos que permitem aos jovens classificar-se e classificar aos demais, ao mesmo tempo em que produzem uma redefiniç̧ão, de caráter local, do consumo destes espaços e seus bens.

Desenho arquetetônico, música, decoração, integração funcional, eventos, motivação publicitária, anúncios, exibição de bens, tudo conflui para dar forma e atmosfera comercial que do que existe no interior destas grandes superfícies comerciais e recreativas, onde se respira o fenômeno do consumismo. Dinâmica econômica que se vê complexada com a postura ativa por parte dos jovens que, com suas práticas sociais no interior destes espaços, recriam o cenário no qual encontram-se submerços, com um forte impacto sobre os sistemas socioeconômicos locais.

PALAVRAS CHAVE: JUVENTUDE, CONSUMO, NOVOS OBJETOS URBANOS

\section{ABSTRACT}

This academic work seeks to tackle a discussion in progress about youth; consumption and space, starting by systemize some ideas about the linking between the transformation of the commercial offer and juvenile culture, and move forward in the analysis of their effects on the socio-economic local environments.

In the context of the dynamics that define the reorganization of the metropolitan scenario in Buenos Aires, the larger recreational centers and malls deserve a special treatment since they have set themselves up as urban nodes that internalize resources that allow young people to classify themselves and classify the rest, as well as to produce a complete redefinition - locally characterized - of the consumption of these spaces and their merchandise.

Architectonic design, music, decor, functional integration, special events, advertising incitation, ads, display of products, different aspects converging to give shape to the commercial atmosphere that we can find on the inside of these large commercial and recreational surfaces, where we can breathe the phenomenon of consumerism. An economical dynamic that acquires a complexity because of an active attitude on the part of young people who recreate the space they are submerged in, trough their social practices inside these spaces, generating a huge impact on the socioeconomic local systems.

KEY WORDS: YOUTH, CONSUMPTION, NEW URBAN OBJECTS 


\section{NUEVAS DINÁMICAS Y CREACIÓN DE NODOS DE CONSUMO}

A LO LARGO DE las últimas décadas los grandes aglomerados urbanos se han convertido en el escenario privilegiado de cambios socioeconómicos y políticos, en el marco de la crisis del fordismo y el advenimiento del modelo de producción flexible. La reestructuración urbana, como respuesta a las exigencias en materia de producción e intercambio global, ha sido el resultado de dinámicas estructurales e institucionales que destacan, por un lado, la interacción entre lo local y lo global y, por otro lado, la revalidación de la identidad de cada región como un elemento clave en la nueva economía global.

Las reformas estructurales practicadas en el seno del aparato estatal argentino, junto con los procesos de privatización, desregulación de mercados y apertura, desató nuevas dinámicas al interior del territorio, de fuerte impacto en las esferas económica, social, política y cultural.

La proliferación de estas nuevas dinámicas, que están estrechamente vinculadas a la emergencia de un nuevo modelo de acumulación, guía la mirada al proceso de reestructuración de la RMBA y al recalo de corrientes de capitales que moldearon un espacio urbano dualizado que camina con paso firme hacia la modernización y la profundización de la segregación territorial.

Como señalan Cicolella y Mignaqui (2000:33), «la aparición de estos nuevos objetos urbanos (NOU) que acentúan la fragmentación se caracterizan por arquitecturas aditivas, heterogéneas, efímeras y excluyentes, respondido a procesos especializados propios de la nueva cultura urbana. También alteran la morfología, el tejido y el paisaje urbano, así como los usos del suelo, las funciones, las actividades económicas predominantes y los mercados de trabajo de cada fragmento urbano (barrio, partido, etc.), afectando o poniendo en tela de juicio, en muchos casos, su propia identidad».

Como afirma Wortman (1998:3), refiriéndose a Buenos Aires, «si bien es posible encontrar rasgos que hacen a su peculiaridad, podemos percibir nuevas formas del design internacional tanto en la construcción de shoppings, con multicines y nuevas formas de propagación del ocio, como en el aumento de autopistas, bares temáticos con internet así como la transformación de bares y restaurantes tradicionales en espacios culturales vidriados».

El espacio del medio urbano construido, integrado por los grandes centros comerciales y recreativos, merece una especial atención 
dado que se han erigido como focos de atracción privilegiados de las Inversiones Extranjeras Directas (IED) con una magnitud de cinco mil millones de pesos (Ciccolella, 2000:470), y tienen estrecha vinculación con la emergencia de nodos urbanos privilegiados de consumo y producción, material e inmaterial, de la población juvenil. Locus de socialización y encuentro, donde se despliegan las prácticas que permiten su identificación y la realización de lo juvenil, elementos esenciales para el tránsito hacia los roles adultos.

La redefinición, con carácter local, del consumo de estos espacios y sus bienes, elemento central en este trabajo, exigen la previa conceptualización del término juventud, junto a un breve repaso de la diversidad de acepciones que el mismo tiene, con elementos extraídos de diversas disciplinas como la biología, psicología, sociología, ciencias políticas y antropología.

\section{HACIA UN CONCEPTO DE JUVENTUD}

El término juventud, en la concepción más general, hace referencia al período temporal en que los individuos transitan desde la niñez a la condición adulta, pasajes en el que se evidencian importantes cambios biológicos, psicológicos, sociales y culturales.

En las sociedades modernas los conceptos como infancia, juventud o vejez, se presentan como categorías imprecisas, con fronteras borrosas y de difícil discernimiento, cuadro que hace alusión al debilitamiento de los rituales de pasaje ante el desmembramiento de las instituciones tradicionales que operan en el plano económico, social y cultural. Además, deberá señalarse que cada una de las transformaciones entrañan características de diferente tinte que responden a diferenciales en el estadio de desarrollo alcanzado por las sociedades.

En medio de estas indefiniciones, se plantea la necesidad de establecer alguna convención, a fines operacionales, que materialice las fronteras de la juventud. El entorno principal para aprehender el espacio de lo juvenil está dado por la edad, aunque existe un intenso debate en torno a la operacionalidad de la delimitación etaria, en línea con el establecimiento de la cota superior, ante el creciente reconocimiento del ensanchamiento del ámbito de la juventud, con inédito alcance en el clima contemporáneo.

Así, los jóvenes se corresponden con un entorno etario que varía según el contexto económico, social y cultural en el que se desenvuelven, pero que en general se ubica entre los 15 y los 24 años, aunque en 
el caso de los estratos sociales medio y superior se amplía para incluir al grupo de 25 a 29 años (CEPAL, 2000). Si bien, estas definiciones estadísticas pueden ser cuestionables en cuanto al entorno etario elegido, cabe destacar que dichos límites convencionales suelen estar en línea con procesos sumamente relevantes que destacan para la cota inferior al desarrollo de las funciones sexuales y reproductivas, de fuerte impacto en el plano físico, biológico y psicológico, mientras que la cota superior se erige en una esfera de pasaje a la categoría de la vida adulta vinculada al cierre del ciclo educativo formal, el ingreso en el mercado laboral y la formación de un hogar propio.

La utilización de la categorización etaria de modo de establecer el espacio de la juventud, ha recibido respuestas críticas provenientes de la literatura sociológica reciente, destacando la íntima relación que guarda el logro de la madurez social y el lugar ocupado por el cuerpo social, exhibiendo una multiplicidad de maneras de ser joven.

Se ha puesto de manifiesto que, si bien la juventud posee una dimensión simbólica de importancia sublime para este trabajo, también exige el análisis posar la mirada sobre los aspectos materiales presentes en toda producción social.

A la base de estos argumentos se encuentra la noción de moratoria social, la cual se erige en clara discordia con el uso de la categorización etaria, al no distinguirse las condiciones desiguales en que se encuentran individuos de diferentes sectores sociales pertenecientes al mismo grupo etario. Así, los jóvenes de sectores medios y altos tendrán oportunidades de postergar su ingreso a las responsabilidades de la vida adulta gozando de un menor grado de exigencia que sus pares pertenecientes a los estratos superiores, y por una período más prolongado de los signos de la juventud (Margulis y Urresti, 1998a).

Ser joven implica la posesión de una moratoria vital, un crédito temporal, energía vital cuya durabilidad estará determinada social y culturalmente, «lo sociocultural influirá en los ritmos de desgaste biológico, haciendo pesar la diferenciación social en la mera cronología» (Margulis y Urresti, 1998a:23).

A continuación, se analizará cómo los grandes equipamientos comerciales y recreativos se transforman en recortes urbanos con elementos que permiten el reconocimiento en línea con una determinada identidad social que se palpa a través de mensajes emitidos por la forma de exhibir las prendas, la escenografía de sus pasillos, la composición de símbolos y colores utilizados, el lenguaje y las posturas corporales, entre otros. 


\section{COMPOSICIÓN DE LA DEMANDA Y CONSUMO MATERIAL Y SIMBÓLICO}

A la par que en este conglomerado metropolitano iban apareciendo grandes equipamientos de consumo, cuyos patrones arquitectónicos y de servicios ponían de relieve una clara vocación por erigirse como espacios de apropiación colectiva, fragmentos del medio urbano de encuentro y socialización, con dirección hacia la juventud, los integrantes de esta última, se encontraban, evidentemente, con obstáculos que dificultaban su tránsito hacia los roles adultos.

El acceso de los jóvenes a los servicios de educación, trabajo, salud y vivienda, exhiben un nivel de cobertura que mengua el gratificante colectivo por la emergencia de dichos nodos, al privar a los sectores bajos, la gran porción de la población juvenil, del consumo, físico y simbólico, del espacio y los bienes y servicios ofertados.

En este ámbito se hace palpable este doble movimiento que recorre la relación juventud y sociedad en toda su extensión, signado por la exaltación de los signos de la juventud y el ahondamiento del acceso a un umbral que permita el despliegue, en muchos jóvenes, del sentimiento de adecuación social.

En efecto, de una parte, sufren el impacto de demandas y modelos según los cuales la juventud aparece como un valor supremo y todo lo que es joven es valorado como lo único que tiene sentido. De otro lado, cada vez les es más difícil asumir responsabilidades en los diferentes ambientes sociales (Rubiolo, 1997:163).

La publicidad de bienes y servicios que oxigena incansablemente al fenómeno del consumismo, contiene una clara estrategia de exacerbación del deseo y la necesidad por la incorporación de los mismos, creando sentimientos de frustración y fracaso que repercute en la representación que los jóvenes tienen de sí mismos.

Las grandes superficies comerciales y recreativas emergen como locus del medio construido que internalizan recursos que permiten a los jóvenes clasificarse y clasificar a los demás, en línea con un consumo determinado.

La mencionada estrategia de seducción que la sociedad ejerce sobre la juventud aumentando indudablemente el narcisismo y la histeria que son de por sí características psicoafectivas de los adolescentes y jóvenes... Hay una necesidad casi compulsiva de mostrarse (histeria), y de exhibirse. Ésta satisface al narcisismo, aunque para ellos deben alcanzarse los estándares de belleza que la sociedad estipula (Rubiolo, 1997:163). 
Resulta claro que sobre el consumidor convergen una multiplicidad de estímulos: productos, anuncios, decoración, precios, recomendaciones, etc., transformando a todo acto de compra en el resultado de impresiones complejas de las cuales los consumidores no son plenamente conscientes, Lo verdaderamente importante es entender que las cosas son percibidas subjetivamente al dar significado a los estímulos que le llegan (León y Olabarría, 1993).

Se hace presente la referencia al aceleramiento del ritmo de producción económica, tanto en su mundo real como simbólico, que desencadenan el lanzamiento de nuevos productos que se suceden unos a otros impulsando el acortamiento de la vida de las formas simbólicas que operan en la sociedad.

En este esquema, la moda juega un papel fundamental en la definición de los contenidos del mundo juvenil y la distribución social de los recursos que sirven de soporte para la determinación de la condición de juventud, generando distintas formas de ser joven. Debido a que la moda produce la obsolescencia anticipada de los bienes, a partir de erosionar el valor simbólico, de espaldas al desgaste material, impacta sobre el dinamismo de la demanda, con particularidades asociadas a la posesión de recursos en su interior, pero con un claro apetito de adquisición a la par que se exalta la función signo de los consumos de espacios, bienes y servicios (Margulis y Urresti, 1998b).

Los objetos urbanos se erigen como espacios en donde la dimensión connotativa de los bienes y servicios insertos en una escenografía cuidada se refuerza; además, se presentan en lugares donde los jóvenes se interiorizan acerca del cuerpo legítimo masculino y femenino, a la vez que adquieren el saber práctico que les permite encubrir la distancia entre su cuerpo y el cuerpo legítimo, y utilizándolo así como instrumento de seducción (Ariovich, Parysow y Varela, 1998).

Se pone de manifiesto, que en los sectores medios y altos, se produce el consumo físico y simbólico del medio y los bienes y servicios que allí se ofrecen, vía la apropiación efectiva de las mercancías o la incorporación de la dimensión connotativa que poseen. La expresión de lo juvenil en los grandes emprendimientos comerciales por parte de los sectores bajos de la población juvenil se ve acotada debido a la carencia de recursos que deviene de una deficiente integración social, situándolos en los límites mismos de la exclusión y la marginación.

Un aspecto de particular relevancia para este estudio es la captura conceptual del hecho que los jóvenes consumen en términos materiales y simbólicos, en forma directa e indirecta, las unidades comerciales y 
recreativas a través del consumo material y simbólico, directo e indirecto, de los bienes y servicios ofrecidos en dichos establecimientos.

El consumo material y simbólico, tanto del espacio como de las mercancías, hace referencia al consumo efectivo, físico, de los elementos señalados y la incorporación de los signos connotativos de los mismos, respectivamente. Mientras que el carácter directo e indirecto del consumo de los espacios y las mercancías hace alusión, por un lado, a la fortísima interrelación que existe entre ambos, y por el otro, al hecho que la incorporación de un ejemplar de las especies hace automática referencia a ambas.

Así, los jóvenes de los sectores medios y altos consumen la dimensión material y simbólica, directamente, de los equipamientos comerciales y recreativos a través de sus prácticas sociales, al presentarse como espacios dedicados al ocio y como nodos de encuentro y socialización, o el consumo, en ambas direcciones, de los bienes y servicios que integran la oferta de dichos nodos.

El plano indirecto del consumo de dicho espacio alude al impacto que tienen en el conjunto comercial y recreativo, las prácticas mencionadas y la incorporación, material y simbólica, de las mercancías; postulando el traspaso de la dimensión espacial de lo acontecido en cada unidad, al conjunto.

De observarse la población juvenil en condiciones de participar de dichas prácticas e integrarse socialmente en dicho contexto, podría parecer desmedida la proliferación de estos centros comerciales y recreativos en el aglomerado. Sin embargo, este aparente desfasaje entre la oferta y demanda encontrará respuesta al rastrearse un conjunto mayor que el captado por criterios demográficos.

Resulta interesante remarcar que este diferencial que haría arribarse a un resultado de exceso de oferta, medida en metros cuadrados, dedicada al urbanismo comercial y recreativo se ve compensado por un complejo proceso de anexión a las filas de la juventud de una porción de la población adulta a partir de la mercantilización de los signos de la juventud.

Así, la juventud integra signos exteriores que, en virtud del patrón estético dominante, contiene un valor simbólico apreciado que ha desencadenado en la comercialización de dichos atributos corporeizados en mercancías que integran la oferta de los objetos urbanos mencionados. Cumpliendo con los mandatos sociales imperantes, los adultos buscan empaparse de juventud. Se idealiza el mundo juvenil al destacarlo como un ambiente en donde mora el goce estético, realzan- 
do su salud y felicidad, y tratando de apartarse del deterioro de las virtudes corporales y el envejecimiento.

El juego social que practican los adultos atraídos por el estereotipo juvenil, claramente, obstaculiza el proceso de construcción de identidad en muchos jóvenes, a la par que se da un esfuerzo fuerte, por parte de la industria de la estética y el ocio, por hacer tangibles los signos que la juventud detenta.

Debido a que la morfología, el diseño interior, la división funcional de estos espacios, y el paisaje urbano en el que son inscriptos, integran elementos de vital importancia en la construcción del hábitat de los jóvenes; estos últimos, adoptan una participación activa en términos de la reconstrucción de los espacios de consumo a partir de la interacción con su medio. El carácter recreador de las prácticas descriptas lleva la mirada al impacto en el territorio y los ambientes locales socioeconómicos.

\section{REDEFINICIÓN LOCAL DEL CONSUMO Y LOS AMBIENTES SOCIOECONÓMICOS}

En el ámbito de la producción, el esquema de los distritos industriales de Marshall, tienen una fuerte presencia, ya que dirigen su atención a la creación de competencias con un claro comportamiento local que enlaza recursos sociales, económicos, políticos y culturales de un territorio.

Debe entenderse que no se está haciendo referencia a una accidental concentración geográfica de firmas en un determinado espacio, sino que el territorio actúa como un verdadero soporte de las redes productivas y los sistemas locales económicos y sociales. El elemento clave para desarrollar competencias en este esquema es su capacidad para desatar sinergias en el entramado productivo como consecuencia de esta organización y actuación en conjunto.

En su interior se construye una red de intensas relaciones internas que marcan la existencia de un sistema de valores e ideas compartidas respecto de la organización productiva, la infraestructura, la cultura y la malla institucional. Aquí es donde se propone el salto hacia la esfera del consumo en los espacios que analiza este trabajo.

Cuidado arquitectónico, música, decoración, integración funcional, eventos, incitación publicitaria, exhibición de mercancías, todo confluye para dar forma a la atmósfera comercial que mora al interior de estas grandes superficies comerciales y recreativas, donde se respira el fenómeno del consumismo. 
La atmósfera comercial, haciendo un paralelismo con la atmósfera industrial marshalliana, genera dinamismo interno, impulsa el aprendizaje compartido, desarrolla las capacidades empresariales, despliega el conocimiento codificado y sin codificar. El cúmulo de imágenes y sentidos, emergidos de los atributos reales e imaginarios del espacio y las mercancías, utiliza como canal de contacto interpersonal a un lenguaje común, creación específica de ese ambiente, subproducto determinado de tres dimensiones: la espacial, la temporal y la de las relaciones.

Esta dinámica económica se ve complejizada con la postura activa por parte de los jóvenes que con sus prácticas sociales al interior de los espacios comerciales y recreativos recrean el escenario en el cual se encuentran sumergidos. Los jóvenes reconstruyen el ambiente con sus prácticas, en donde interviene un proceso de producción secundaria; al decir de De Certeau:

Las palabras consumidor... la sustituyó por la de practicante, y lo que me interesa es el uso que esos practicantes hacen del espacio urbano construido, de los sistemas de productos organizados en el supermercado, o el uso que hacen de los relatos y pies de ilustraciones distribuidas por el período habitual. En todo esto hay una fabricación cuyo autor es el practicante... es una producción, pero permanece oculta... Esta producción no queda marcada por productos propios, sino que se caracteriza por maneras propias de emplear los productos difundidos e impuestos por un orden económico dominante» (De Certeau, 1979; citado en Ariovich, Parysow y Varela, 1998:37).

Cabe hacer referencia a la fuerte influencia de la cultura en el comportamiento de los consumidores que no puede explicarse únicamente por variables personales como las necesidades, motivaciones y actitudes. Sin embargo, en este cuadro debe dirigirse la atención a la construcción de subculturas, de carácter local, con una clara identificación socioterritorial, en el que hay una clara contribución de la subcultura de la edad en el resultado expuesto al interior de los espacios comerciales y recreativos.

El mercado de los jóvenes es importante, no sólo porque es lucrativo, sino también porque muchas costumbres de consumo que desarrollarán durante el resto de sus vidas la conforman en este ciclo. Esta es la etapa en que las lealtades a marcas se crean. A esta edad se sienten fascinados por los productos nuevos y las marcas (León y Olabarría, 1993:154).

La remodelación del espacio público que realizan los jóvenes arrastra la dilusión del carácter atomizado y autárquico de las acciones, exhi- 
biéndolas como un producto colectivo de una comunidad que crece y sobrevive al interior de un ambiente con reglas e instituciones comunes compartidas.

Es palpable que los ámbitos de consumo material o simbólico, de forma directa e indirecta, la sedimentación de valores, la integración de las prácticas y la redefinición del espacio construido implican una resignificación de los elementos territoriales locales, de vital importancia no sólo para la trama de relaciones socioeconómicas en el plano productivo, sino también en la esfera del consumo.

En concordancia con lo descripto, Beccantini y Rulliani (1996:413) señalan que «tanto la producción como el consumo son fenómenos irreductiblemente localizados, es decir, determinados íntimamente por las características específicas del sistema territorial al que pertenecen. Se produce o se consume en un lugar: la producción y el consumo son procesos complejos en los que entran en juego la calidad material e inmaterial del lugar, al ser un nexo de relación y al tener historia que lo hace distinta de otro lugar»».

El territorio, como unidad físico-social, se presenta como la materialización de la síntesis, fruto del movimiento dialéctico de fuerzas dinamizantes económicas, sociales, políticas y culturales. El nuevo rol del territorio enmarcado en la producción de espacios para jóvenes exige invitar al análisis a los agentes territoriales vinculados a la producción y distribución de las mercancías que tiene como destino a estos objetos urbanos u otros sustitutos, los canales de acceso en línea con la accesibilidad de dichos puntos y la conectividad de la red, el control y el cuidado de las instalaciones, la seguridad ciudadana.

El arribo de jóvenes a esos establecimientos deberá verse a la luz de elementos como la proximidad geográfica de centro comerciales y recreativos, de sustitución parcial como galerías comerciales, pubs, salas de cine, complejos deportivos; la conexión con estos nodos vía el sistema público común, de particular importancia en el extremo inferior de la cota etaria sin acceso a la autonomía que brinda el automóvil particular, la seguridad presente en el medio urbano circundante y el control al interior de los espacios que no sólo se vinculan con los servicios de vigilancia interna, sino también en cuestiones asociadas con el cuidado y apego a normas medioambientales, de atención médica, de prevención de accidentes y tratamiento de catástrofes, etc.; además deberá incluirse el disfrute de los servicios de estacionamiento, horarios flexibles y eventos espectáculos culturales públicos. 
La invasión de los grandes centros comerciales y recreativos al área metropolitana puede enmarcarse, insertos en la teoría del ciclo del producto, en la instancia de agotamiento de las rentas obtenidas en los mercados de origen de esta modalidad de gran distribución, en Francia, España y EE.UU. Situación que devino en una incorrecta lectura acerca de las necesidades en términos de regulación que estas grandes superficies necesitaban, teniendo en cuenta el impacto urbanístico producido y las particularidades del comercio nacional, replicando los errores cometidos en las instancias de política de los mercados señalados.

\section{CONCLUSIONES}

Un aspecto de particular relevancia para este estudio es la captura conceptual del hecho que los jóvenes consumen en términos materiales y simbólicos, en forma directa e indirecta, las espacios y los bienes y servicios ofrecidos en dichos establecimientos produciéndose un fértil entrecruzamiento que realza el valor local del consumo.

La morfología, el diseño interior, la división funcional de estos espacios, y el paisaje urbano en el que son inscriptos estos grandes centros, integran elementos de vital importancia en la construcción del hábitat de los jóvenes. A la vez que puede rastrearse una participación activa por parte de los jóvenes en términos de la reconstrucción de los espacios de consumo a partir de sus prácticas.

Una multiplicidad de elementos, como el diseño interior, música, decoración, integración funcional, eventos, publicidad, anuncios, posturas corporales, lenguaje, todo confluye para dar forma a la atmósfera comercial que vive al interior de estos grandes espacios comerciales y recreativos.

Esta invitación a reposar la mirada en los componentes locales de esta dinámica económica realza la importancia de sus efectos sobre los ambientes locales económicos y sociales, lo cual abre el juego a la puesta en marcha de políticas públicas para impulsar el desarrollo de competencias y habilidades distintivas.

Buenos Aires (ARgENTINA), AGOSTO 2004

RECIBIDO: AGOSTO 2004

ACEPTADO: NOVIEMBRE 2004 


\section{BiBLIOGRAFÍA}

ARIOVICH, L.; J. PARYsow y A. VARela (1998): «Juegos en el shopping center». En MARIO MARGULIS (editor): La juventud es más que una palabra. Ensayos sobre cultura y juventud. Buenos Aires: Editorial Biblos.

Beccantini, G. y E. RUlliani (1996): «Sistemas productivos locales». ICE N754, junio.

CEPAL (2000): Juventud, población y desarrollo. Santiago: CEPAL.

Ciccolella, P. (2000): «Distribución global y territorio. Modernización y concentración comercial en Argentina en los años noventa». Economía, Sociedad y Territorio, Vol. II, Nº7. México: El Colegio Mexiquense.

e I. MignaQUi (2000): «Economía global y reestructuración metropolitana. Buenos Aires ¿ciudad global o ciudad dual del siglo XXI?». Cuadernos del CENDES $\mathrm{N}^{\circ}$ 43. Caracas: Universidad Central de Venezuela.

LeÓN, J. L. y E. OlABARRÍA (1993): Conducta del consumidor y marketing. Buenos Aires: Espasa Calpe/Deusto.

MARgulis, MARio y MARCElo URResti (1998a): «La juventud es más que una palabra». En MARIO MARGULIS (editor): La juventud es más que una palabra. Ensayos sobre cultura y juventud. Buenos Aires: Editorial Biblos.

- y - (1998b): «Moda y juventud». En MARIO MARGULIS (editor): La juventud es más que una palabra. Ensayos sobre cultura y juventud. Buenos Aires: Editorial Biblos.

WORTMAN, A. (1998): «Representaciones massmediáticas de los consumos culturales porteños». En Cuartas Jornadas de Investigación de la Cultura, Buenos Aires. 